\section{Meanings of microalbuminuria in idiopathic nephrotic syndrome in children}

\author{
Richard Loumingou* \\ Nephrology Service of the C.H.U. of Brazzaville, Republic of the Congo
}

\section{Abstract}

We investigated the existence of microalbuminuria in children with corticosteroid-sensitive idiopathic nephrotic syndrome in complete remission. In the study of a series of 18 cases, we noted a clearly different evolution depending on the existence or absence of pathological micro albuminuria.

Microalbuminuria appears to be a prognostic discrimination parameter in idiopathic nephrotic syndrome.

\section{Introduction}

Microalbuminuria is an early marker of renal dysfunction and cardiovascular risk [1]. The place of microalbuminuria has never been discussed in nephrotic syndrome. This study suggests a correlation between microalbuminuria and idiopathic nephrotic syndrome in children.

\section{Patients and methods}

We followed 18 children with primary nephrotic syndrome for 4 years.

We have included in the study:

Children who had nephrotic syndrome defined as:

- $\quad$ Ptroteinuria greater than or equal to $50 \mathrm{mg} / \mathrm{kg} /$ day

Excluded were children with inflammatory diseases, infectious diseases, and secondary nephrotic syndrome.

All children were treated with prednisone then $2 \mathrm{mg} /$ $\mathrm{kg} / 2$ days, then $2 \mathrm{mg} / \mathrm{kg} / 2$ days as soon as the proteinuria was negativated.

The parameters studied were:

\section{- 24 hours proteinuria}

In all the children we performed a monthly dosage of 24-hours proteinuria.

In children who had negative proteinuria during the course of treatment we performed the microalbuminuria

\section{More Information}

*Address for Correspondence: Richard

Loumingou, Nephrology Service of the C.H.U. of Brazzaville, 1 Boulevard Auxence Ickonga, Republic of the Congo, Tel: +2420666033 69; Email: richardloumingou@gmail.com

Submitted: 25 March 2020

Approved: 09 April 2020

Published: 13 April 2020

How to cite this article: Loumingou R. Meanings of microalbuminuria in idiopathic nephrotic syndrome in children. J Clini Nephrol. 2020; 4: 014-015.

DOI: 10.29328/journal.jcn.1001051

Copyright: (c) 2020 Loumingou R. This is an open access article distributed under the Creative Commons Attribution License, which permits unrestricted use, distribution, and reproduction in any medium, provided the original work is properly cited.

Keywords: Nephrotic syndrome; Microalbuminuria; Children

Check for updates

OPEN ACCESS

assay. We used the ratio of microalbuminuria to creatinuria on one micturition and considered positive a ratio higher than $200 \mathrm{mg} / \mathrm{mmol}$; we performed 2 to 3 determinations in all children.

Microalbuminuria was then measured once a month at the same time as proteinuria in children who had consistently negative proteinuria throughout the course of the disease.

Creatinine and uroculture were also performed on a monthly basis.

\section{Results}

12 children between the ages of 6 and 14 were selected.

5 children had negative proteinuria and negative microalbuminuria (Group 1), and 7 children had negative proteinuria and positive micro albuminuria (Group 2).

Group 1: The evolution was marked by a persistent negative proteinuria and negative microalbuminuria after 24 months ( 2 children) and 30 months ( 3 children) follow-up.

Group 2: The evolution was marked by corticodependence or corticoresistance.

4 children had developed a corticodependence characterized by 2 consecutive relapses when the corticosteroids were withdrawn, or 2 weeks after they were stopped. 
2 children progressed to corticosteroid resistance defined by the persistence of nephrotic syndrome after 4 weeks of well-conducted conventional treatment and despite the use of a $15 \mathrm{mg} / \mathrm{kg} /$ day corticosteroid bolus for 3 days.

1 child experienced partial remission characterized by the recurrence and persistence of low proteinuria of less than $10 \mathrm{mg} / \mathrm{kg} /$ day.

\section{Discussion}

Therearenoreportedstudies evaluatingmicroalbuminuria during pediatric nephrotic syndrome.

Microalbuminuria is a sign of generalized endothelial dysfunction.

Nephrotic syndrome is caused by damage to the glomerular basement membrane and podocyte cells [2].

Minimes Glomerular Lesions is the most common form of primary nephrotic syndrome in children; it is corticosensitive in almost $90 \%$ of cases but is multi-recurrent [3].

Microalbuminuria found during the remission phase of proteinuria would be predictive of an unfavorable evolution. Negative microalbuminuria associated with negative proteinuria would be a favorable element.

Several hypotheses are put forward to explain micro albuminuria of nephrotic children. Are these children born to hypertensive parents? The existence of microalbuminuria in these children has been reported [4].
Are they atopic children? Atopy could be a vascular risk factor [5].

Are there Segmental Focal Hyalinosis lesions? Resistant or recurrent Minimes Glomerular Lesions are sometimes associated with Segmental Focal Hyalinosis lesions.

Negative microalbuminuria could be related to exclusive Minimes Glomerular Lesions? And the presence of microalbuminuria suggestive of Segmental Focal Hyalinosis lesions or corticosteroid-resistant nephrotic syndrome.

\section{Conclusion}

Microalbuminuria appears to be a prognostic discrimination parameter in idiopathic nephrotic syndrome in children.

\section{References}

1. Viberti GC, Hill RD, Jarrett RJ, Argyropoulos A, Mahmud U, et al. Microalbuminuria as a predictor of clinical nephropathy. Lancet 1992; 1: 1430-1432.

PubMed: https://www.ncbi.nlm.nih.gov/pubmed/6123720

2. Schorn R, Bleish J. Syndrome néphrotique de l'adulte. Forum Med Suisse. 2013; 13: 527-532.

3. Grimbert P, Audard V, Remy P, Lang P, Sahali D, et al. Recent approaches to the pathogenis of minimal change nephrotic syndrome. Nephrol dial transplant 2003; 18: 245-248.

PubMed: https://www.ncbi.nlm.nih.gov/pubmed/12543875

4. Okpere AN, Anoche IC, Eke. Prévalence de la microalbuminurie chez les enfants du secondaire. Afr Health Sci. 2012; 12: 140-147.

5. Siverber JL, Becker L, Kwasny M, Menter A, Kordoro KM, et al. Central obesity and high blood pressure in pediatric patient with atopic dermatitis. Jama Dermatol 2015; 151: 144-152.

PubMed: https://www.ncbi.nlm.nih.gov/pubmed/25536049 